\title{
EVALUATION OF URBAN MULTI-SCALE LANDSCAPE ECOLOGICAL PATTERN BASED ON OPEN SPACE CLASSIFICATION: A CASE STUDY IN XINXIANG, CHINA
}

\author{
MAO, D. ${ }^{1,2,3}-$ ZhANG, Y. C. ${ }^{3}-$ KonG, D. Z. ${ }^{2}-$ HE, S. L. ${ }^{1,2,3^{*}}-$ LI, X. Y. ${ }^{2}$ \\ ${ }^{1}$ Postdoctoral Research Base, Henan Institute of Science and Technology \\ Xinxiang, Henan 453003, China \\ ${ }^{2}$ College of Forestry, Henan Agriculture University, Zhengzhou, Henan 450002, China \\ ${ }^{3}$ School of Horticulture and Landscape Architecture, Henan Institute of Science and \\ Technology, Xinxiang, Henan 453003, China \\ *Corresponding author \\ e-mail: maoda@foxmail.com \\ (Received $11^{\text {th }}$ Jul 2018; accepted $13^{\text {th }}$ Sep 2018)
}

\begin{abstract}
The past ten years have been a period of rapid urbanization in China, and are meaningful to evaluate urban landscape ecological pattern of this period. The urban landscape can be divided into the architectural space and 6 types of open space with different functions. Based on this kind of classification, this study used an urban area with $101 \mathrm{~km}^{2}$ to evaluate landscape ecological pattern. This study chose 4 indices, namely, Patch density, Landscape shape index, Contagion index and Shannon's diversity index. Using ArcGIS and Fragstats, this study evaluated the landscape ecological patterns of various scales and multiple time points in the case area. The study found that at the macro level, except for the Patch density, which has the relatively obvious growth trend, the landscape ecological pattern indices of other overall levels are not significantly different in time series. However, at the micro level, the spatial differentiation characteristics of each index between $1 \mathrm{~km}^{2}$ spatial units are very obvious and they have great changes according to the different time periods. Therefore, the evaluation of the landscape ecological pattern of the rapidly growing urbanization areas should pay more attention to the spatial unit comparison of the micro level, so as to discover the special areas in the urban space where the landscape ecology is unbalanced and unstable.
\end{abstract}

Keywords: open space system, urban geography, landscape ecology, evaluation

\section{Introduction}

Recently, China has witnessed rapid development of urbanization, and various elements in urban space have undergone drastic changes with rapid urbanization process. In this process, Chinese researchers have carried out many studies in combination with the practical situation of China (Chen et al., 2014; Wu et al., 2014). There are a series of problems to urban landscape ecology that need to be solved. Researchers and institutions have paid more attention to the related urban landscape ecological pattern research. It has been pointed out that the landscape ecological pattern of the city is suitable for observation and evaluation through multi-scale and flexible spatial classification (Li et al., 2010; Jun-Hyun et al., 2016; Grafius et al., 2018).

The ecological pattern of urban landscape should be viewed from the macro and micro level. At the macro level, observe the whole change of indicators, and at the micro level, observe the differences of indicators of different spatial units. The city is a spatially heterogeneous, and complex adaptive system. Landscape pattern and its changes are the results of the interaction of natural, social and biological elements 
(Turner, 2003; Forman, 2016). The intensified human activities lead to fragmentation of landscapes, which have a series of impacts on ecosystems, and damage to the health and integrity of ecosystems, bringing about changes in ecosystem service functions. At the macro level, the city is human habitation, and is often used as a continuous construction site in ecological research. Its internal ecological features are different to express in large-scale space. Meanwhile, at the micro level, because the inner city is divided into different lots by artificial roads, its ecological features and ecological functions are very different from the macro scale.

The main reasons for the study of urban landscape ecology at the micro level are the accuracy of data and the classification of spatial elements (Wang, 2010). In the traditional study, many large scale studies regard 30-m square as a basic grid element. These studies juxtapose urban construction land and forest land, fields, water bodies, etc. which are outside the main urban area as large-scale elements, but ignore the complexity and diversity of urban landscape ecology. The essence of ecological function in urban open space system is that the basic space unit is an organic whole which are associated with each other. The urban green space system was once the main research object of urban landscape ecology. But the analysis and optimization of urban green land mostly stay on the classification of lots on drawings. The green space on drawings has a large subjective qualitative component which cannot reflect the ecological effects such as real green coverage in a region at the middle and micro level and cannot quantify the urban landscape ecological pattern.

Landscape ecological classification is the basis and prerequisite for landscape pattern analysis and landscape function evaluation (Xiao et al., 1998). In recent years, the theory of urban open space systems studied by Chinese domestic scholars has made new developments in spatial classification (Wang, 2005; Wang et al., 2012; Wang, 2010; Shao, 2011; Mao et al., 2016a, b). Open space is a general term of surface space outside the building in the city. Therefore, urban landscape can be divided by the most basic architectural space and the open space. At first, the open space is divided into green open space which represents green coverage and gray open space which represents road, square, waste land, etc. (Wang, 2005). With the continuous study of researchers, the open space can be divided into 6 types: green open space, blue open space (Wang, 2010), light gray open space, dark gray open space, yellow green space ("Production land" in the original paper, Shao, 2011) and brown open space. Together with the architectural space, these six types form the basic landscape classification for our study. The meaning of various types of space can be seen in Table 1 .

Table 1. Table of landscape ecological elements based on open space classification

\begin{tabular}{c|c}
\hline Space classification & Meaning \\
\hline Green open space & Trees, shrubs, lawns and other cities have plants covered space \\
\hline Blue open space & Rivers, ditches, lakes and other water bodies in cities \\
\hline Light grey open space & Piazza, open-air stadium, open car park and outdoor temporary stacking sites \\
\hline Deep grey open space & Urban traffic space, such as road, track, viaduct, etc. \\
\hline Brown open space & Bare land, abandoned land, urban space under demolition and construction \\
\hline Yellowish open space & Agricultural planting areas in urban space \\
\hline Architectural space & The space occupied by buildings in the city or the space beyond the open space \\
\hline
\end{tabular}


This classification method combines the author's thinking on the classification of open space. It has strong identifiability in remote sensing, aerial photography and other resources, and reflects the ecological value of different levels. There were similar practice studies before (Wang, 2010). So study group consider that this open space classification can well reflect the urban landscape pattern. Using this classification method to interpret and classify high-precision satellite imagery cannot only satisfy the macro-scale landscape ecological pattern evaluation, but also meet the micro-scale landscape ecological pattern evaluation.

\section{Case area and data}

\section{Case area}

The study area is located in Xinxiang City, China. Xinxiang City is located in $35^{\circ} 18^{\prime}$ north latitude and $113^{\circ} 54^{\prime}$ east longitude, which is one of the core cities of China's Central Plains urban agglomeration (Fig. 1). Xinxiang City covers an area of $422 \mathrm{~km}^{2}$ and a total area of about $140 \mathrm{~km}^{2}$, with the population of 1.4 million. The research object of this time is the main city of Xinxiang City (Fig. 2). It is surrounded by the loop line which is comprised by four roads. It is $101 \mathrm{~km}^{2}$. The main city area of Xinxiang City is flat and the boundary is composed of four outer loop expressways. It is clear and complete. The traffic in the urban area is basically a square road network. It is an ideal plain landscape ecological city model.

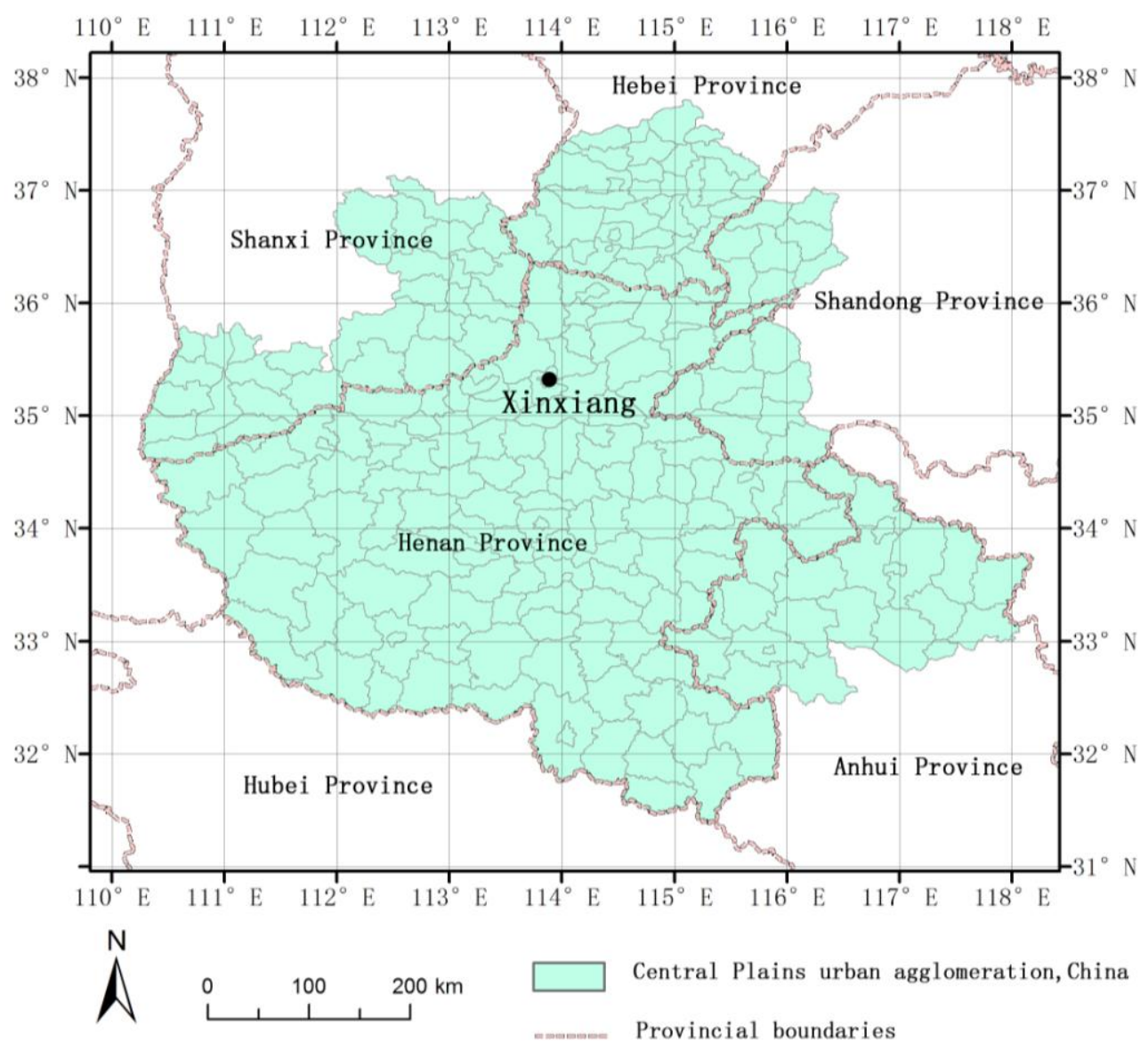

Figure 1. Location map of Xinxiang and Central Plains urban agglomeration 


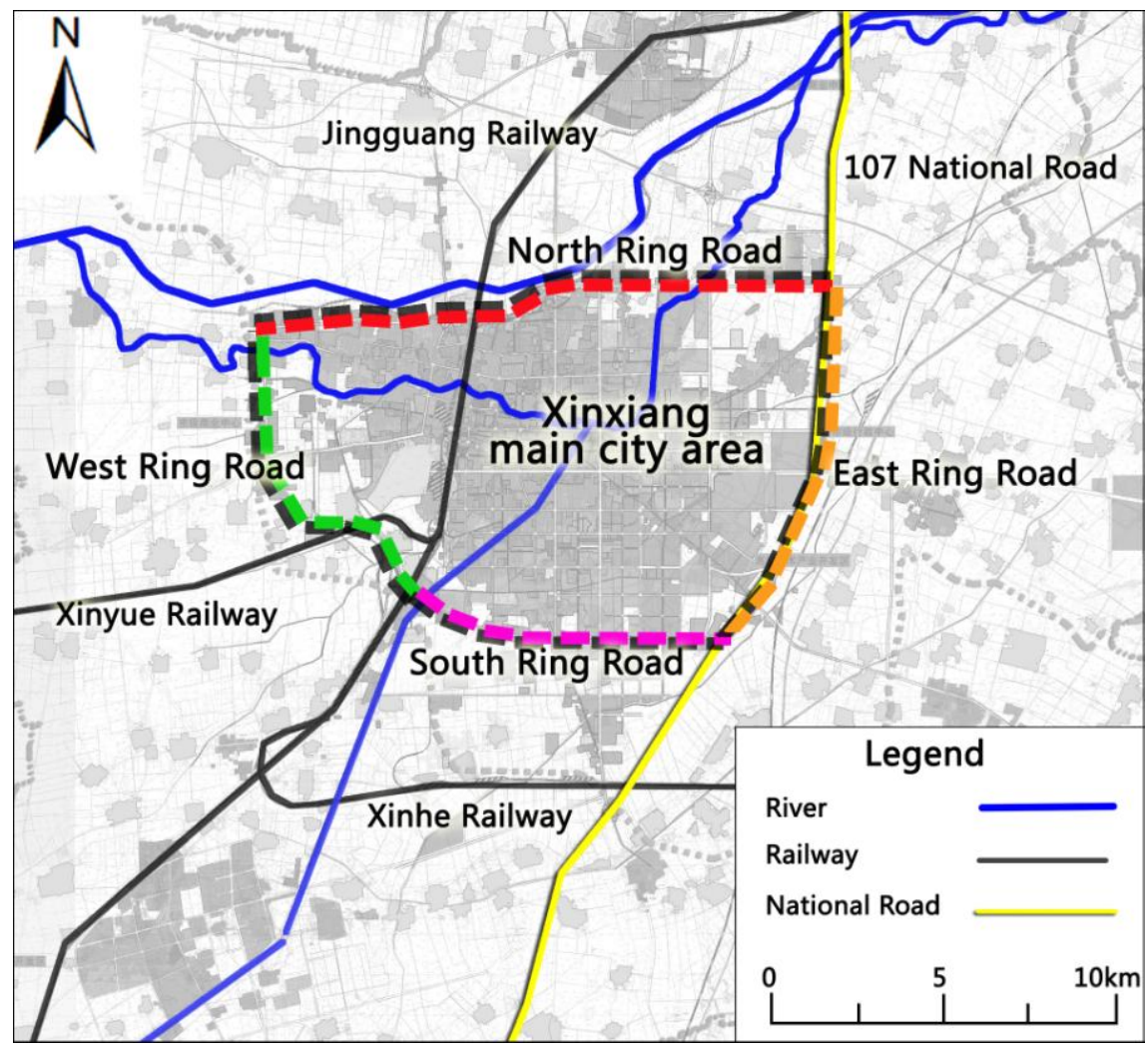

Figure 2. Map of main city area of Xinxiang

\section{Case data}

The study chose time-series high-definition satellite imagery (mostly with $0.85-\mathrm{m}$ resolution, a small amount with $1.85-\mathrm{m}$ resolution), and comprehensively carried out a variety of methods including visual interpretation, and combined with the basic grid unit for refined opening spatial elements extract in categories, so as to achieve full coverage of urban spatial classifications. Finally, in the case area, the classified data resources of 5 time nodes $(2008,2010,2012,2014$, and 2016) were obtained. These data can reflect the spatial and temporal evolution of landscape ecology in the last 10 years of Xinxiang City's main urban area in a more detailed and comprehensive way.

\section{Method}

Many researchers used remote sensing images and related geospatial data as information sources, and used GIS technology and landscape pattern software to classify and analysis. Wang Shengnan divided open space into green, blue, gray and other types in her doctoral dissertation (Wang, 2010), through landscape ecological pattern analysis and other methods were used to analyze the evolution mechanism of the main city area of Luoyang in the process of rapid urbanization. In Shao Dawei's doctoral dissertation, he used remote sensing data and landscape pattern indicators to analyze the spatial evolution of Nanjing (Shao, 2011). At the same time, it is more common to study urban microcosmic spatial analysis with unit grids (Guo, 2016; Gao, 2014). The unit scale of these studies is basically $1 \mathrm{~km}^{2}$. These studies provide an important reference to software selection and index selection of this paper. 


\section{Study software}

The software used in the research mainly includes ArcGIS and Fragstats. ArcGIS is a most used geographic information software in the world nowadays. By using ArcGIS, various kinds of geographic data can be connected and matched. Transformation between vector data and grid data can also be finished. Fragstats are mainly used to deal with landscape ecological pattern index. There are many softwares for analyzing or simulating landscape ecological pattern, such as Fragstats, Patch Analyst, APACK, SIMMAP, etc. Fragstats is a software for calculating landscape index which was developed by the Department of Forest Science at Oregon State University in America. Because it is free and easy to use, it can support a series of landscape pattern index at three levels: Patch Metrics, Class Metrics and Landscape Metrics. At present, Fragstats is a computer program for quantitative analysis of landscape structure and spatial pattern, which can calculate including landscape area, density, size and difference, edge, shape, core lot, nearest neighbor structure, diversity structure, aggregation and dispersion structure and hundreds of indices which are combined with statistics. There are many cases of landscape ecology research using these two software (Hua et al., 2008; Midha and Mathur, 2010; Kupfer, 2012; Ojoyi et al., 2017; Yan et al., 2018). So choosing these two software is very suitable.

\section{Index selection}

Based on the previous research results (Wu, 2007; Hong et al., 2011; Liu et al., 2013), patch density, landscape shape index, contagion index and Shannon's diversity index were selected as analysis indicators in this study.

\section{Patch density}

Patch density (PD) is an index of the number of patches divided by the total area (Wu, 2007), and it is generally used to observe landscape fragmentation (see Eq. 1 for calculation). In the equation, $N$ represents the number of patches and $A$ represents the area. The larger the patch density is, the greater the fragmentation is, so it is regarded as a reverse index in this study.

$$
P D=N / A
$$

\section{Landscape shape index}

The landscape shape index (LSI) is the total length of all plaque boundaries in the landscape $(\mathrm{m})$ divided by the square root of the total area of the landscape $(\mathrm{m})$, multiplied by the square correction constant (Wu, 2007; see Eq. 2 for calculation). In the equation, $E$ is the total length of all patch boundaries in the landscape, and $A$ is the total area of the landscape. In urban space, the high value area of LSI value is usually the area where human activities are dense and the degree of fragmentation is higher.

$$
L S=\frac{0.25 E}{\sqrt{A}}
$$




\section{Contagion index}

Contagion index (CONT) is considered to describe the degree of agglomeration or extension trend of different piecemeal types in the landscape (Wu, 2007; see Eq. 3 for calculation). In the equation, $m$ is the total number of plaque types, and $P_{i j}$ is the probability that two adjacent grid cells randomly selected belong to type $i$ and $j$. Like other indicators of ecological pattern, its significance of the Numbers will vary according to the interpretation of different majors and directions. Generally speaking, the high contagion index indicates that a certain dominant block type in the landscape has formed a good connectivity, while the low value indicates that the landscape fragmentation degree is high.

$$
C \mathrm{NT}=\left[1+\sum_{i=1}^{m} \sum_{j=1}^{n} \frac{P_{i j} \operatorname{In}\left(P_{i j}\right)}{2 \ln (m)}\right](100)
$$

\section{Shannon diversity index}

Shannon diversity index (SHDI) is obtained by multiplying the area ratio of various patches by the negative value of the sum of the natural logarithm of that value ( $\mathrm{Wu}$, 2007; see Eq. 4 for calculation). In the equation, $m$ represents the number of species and $P_{i}$ represents the proportion of individuals belonging to the first species in the sample. In ecology, Shannon's diversity index is a sensitive index, which is generally used to reflect landscape heterogeneity. When the index is 0 , it shows that the patch is a single patch, and the greater the value of the patch is, the more balanced each patch is, and the higher the land use degree is.

$$
\text { SHD }=-\sum_{i=1}^{m}\left[P_{i} \operatorname{In}\left(P_{i}\right)\right]
$$

\section{Research steps}

\section{First item}

This research first carries on the analysis from the macroscopic scale. Taking ArcGIS 10.2 as the basic software platform, the vector data of the case area that has been interpreted and classified are projected and converted into grid data of $1 \mathrm{~m} \times 1 \mathrm{~m}$. Loading raster data into fragstats can quickly get macro-scale indicators.

\section{Second item}

For the microscopic scale, this study chose to generate $1 \mathrm{~km} \times 1 \mathrm{~km}$ grids in the UTM projection coordinate system (Fig. 3), and took each grid as the microscopic observation unit of the case area. In Fig. 3, for ease of study, the researchers digitally represent the abscissa and alphabetically represent the ordinates of the table. Such grid units can be named, for example, A01, A02, etc. At the same time, In ArcGIS, the generated grid is used to cut the transformed grid data, which will allow you to generate hundreds of separate grid files. Then, the batch processing function in fragstats can be used to quickly analyze and get the index value of each unit. 


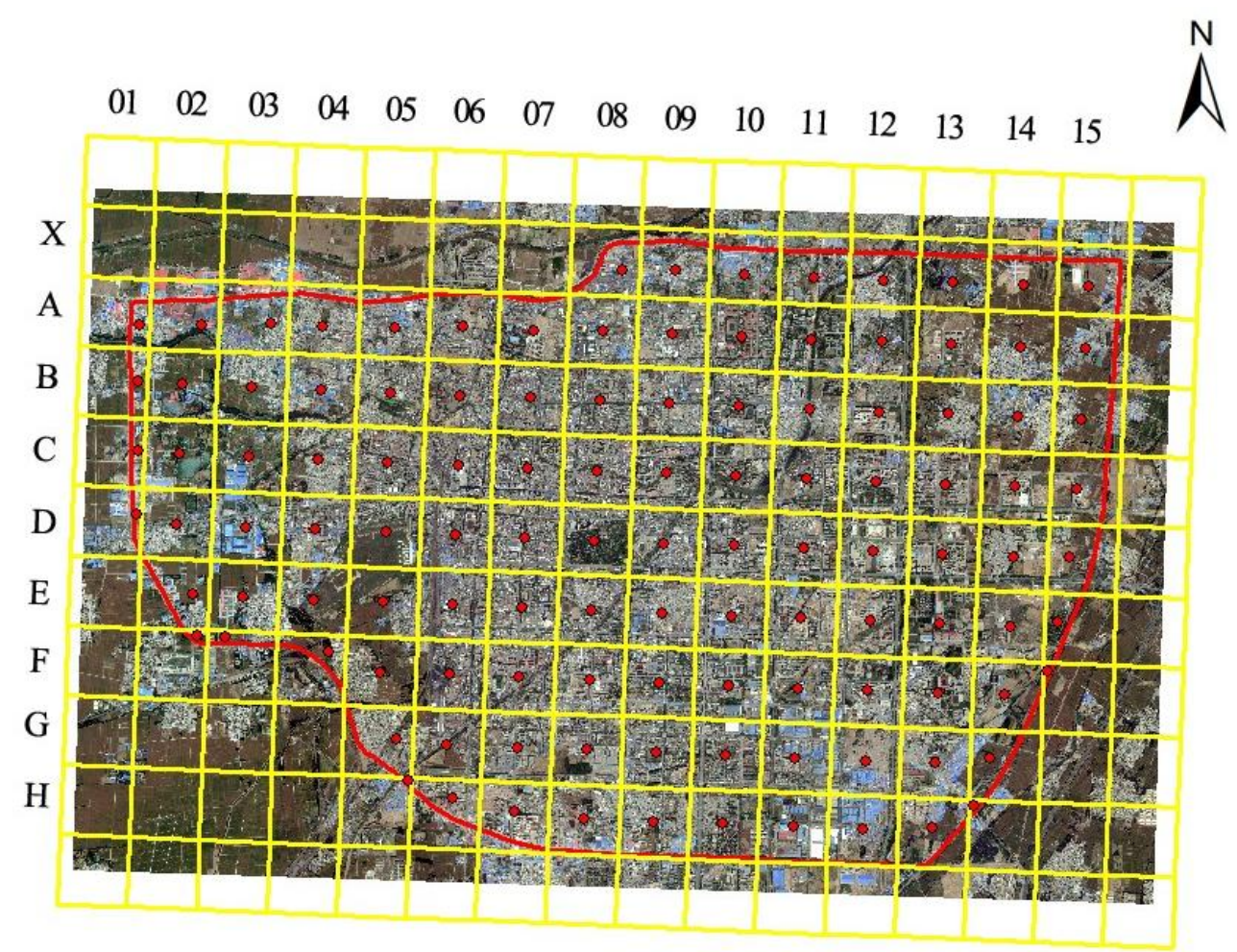

Figure 3. case area satellite picture divided by $1 \mathrm{~km} \times 1 \mathrm{~km}$ grid

\section{Third item}

The spatial unit can be connected with the index in ArcGIS by format conversion of the obtained spatial unit index values. By classifying the connection results, the microscale landscape ecological pattern of the case area can be visualized in ArcGIS.

\section{Results and analysis}

\section{Macro-scale}

This study first used software to calculate the indicators for landscape ecological pattern in case area from 2008 to 2012 (Table 2). Table 2 shows that the number of patches in (NP) declined gradually, while it rose overall from 2012 to 2016, which shows that a certain degree of fragmentation of urban space is not a linear change but dynamic development.

Table 2. Table of indicators for landscape ecological pattern in case area (2008-2016 years)

\begin{tabular}{c|c|c|c|c}
\hline YEAR & $\begin{array}{c}\text { PD } \\
\text { (patch density) }\end{array}$ & $\begin{array}{c}\text { LSI } \\
\text { (landscape shape index) }\end{array}$ & $\begin{array}{c}\text { CONT } \\
\text { (contagion index) }\end{array}$ & $\begin{array}{c}\text { SHDI } \\
\text { (Shannon diversity index) }\end{array}$ \\
\hline 2008 & 482.290 & 167.860 & 47.355 & 1.649 \\
2010 & 468.196 & 169.820 & 46.154 & 1.687 \\
2012 & 466.767 & 168.244 & 47.562 & 1.637 \\
2014 & 509.865 & 177.523 & 46.086 & 1.675 \\
2016 & 493.580 & 173.527 & 47.250 & 1.641 \\
\hline
\end{tabular}


According to the number of different types of patches, the number of blue patches and yellow-green patches decreased linearly, while the number of other types of patches fluctuated. The change of landscape shape index (LSI) is small, showing a fluctuating and rising state, which indicates that the intervention of artificial behavior on the environment has increased to a certain extent. In 2008-2016, due to the solidification of the boundary of the main urban area, the indexes of the overall level, such as contagion index, Shannon's diversity index and aggregation index, all changed little, and the indicators need to be compared with each other in a downsized scale.

\section{Micro scale}

According to Figure 4, there are obvious spatial differences. The scale of the value is obtained by determining the global median and then the arithmetical difference. The minimum value of unit's PD increased from 45 in 2008 to more than 100 in 2016, and the maximum value increased from about 1400 in 2008 to more than 1600, indicating that the rapid urbanization has brought about increased spatial fragmentation. There are continuous units with high patch density in the northwest and central part of the main urban area for a long time. These units belong to the living area of the old city and the small industrial factory area, the buildings are mostly low stories, the building density is generally high, and the open space is broken up seriously. Besides, the patch density of the southeast part of the main urban area is relatively low, the building is generally multi-storey, the high level is high, and the open space is relatively complete.

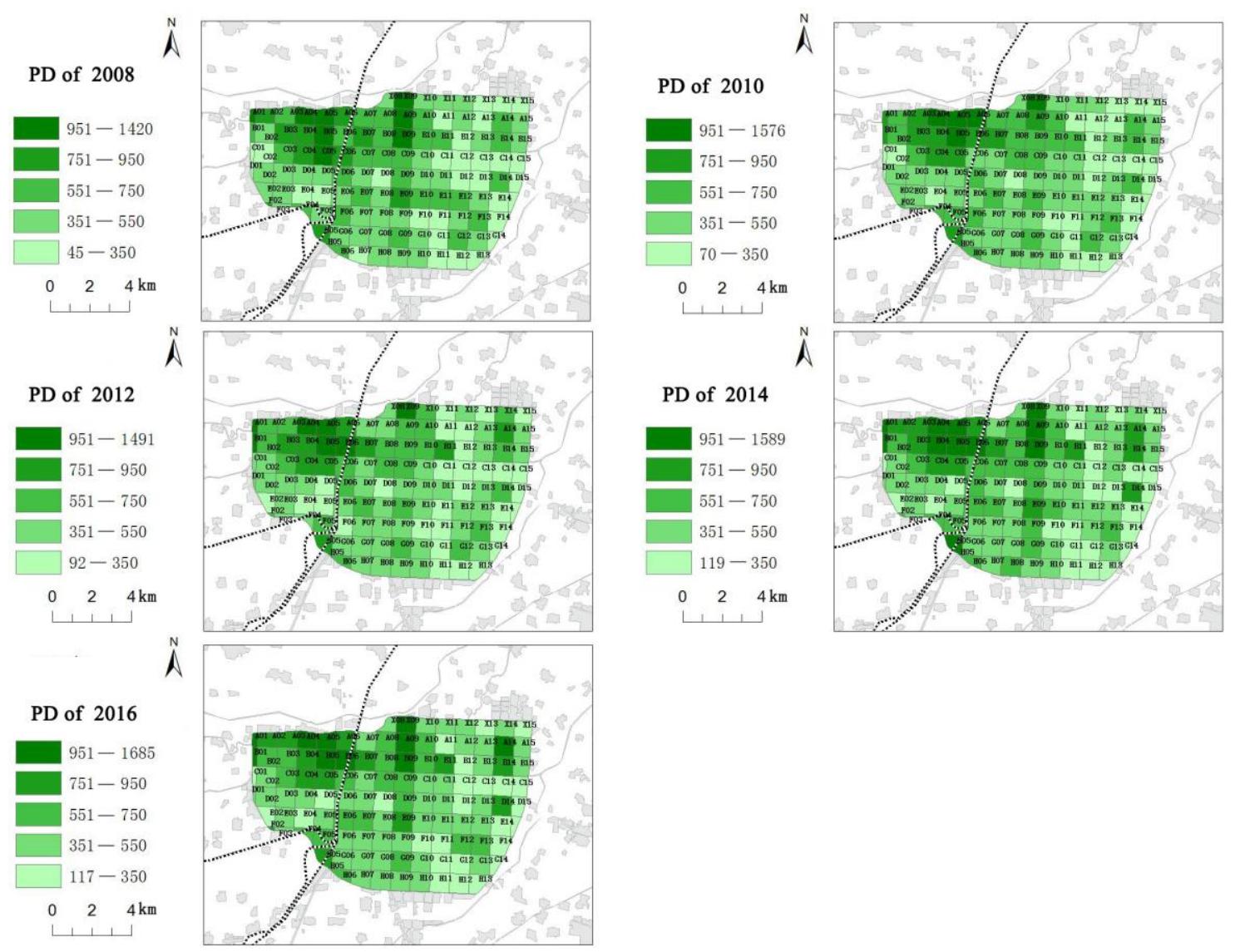

Figure 4. Pattern maps of patch density based on Xinxiang grid units in 2008-2016 
From Figure 5 it can be seen that the difference between the unit and the surrounding area of the people's park is very obvious, and the contrast between the old urban area in the west and the new urban area in the east is also obvious. Green open space, large proportion of yellow and green space landscape shape index are relatively low. Because of the village in the city, the landscape shape index of the east and south of the main urban area is decreasing, while the central and northern land block is in high value for a long time.

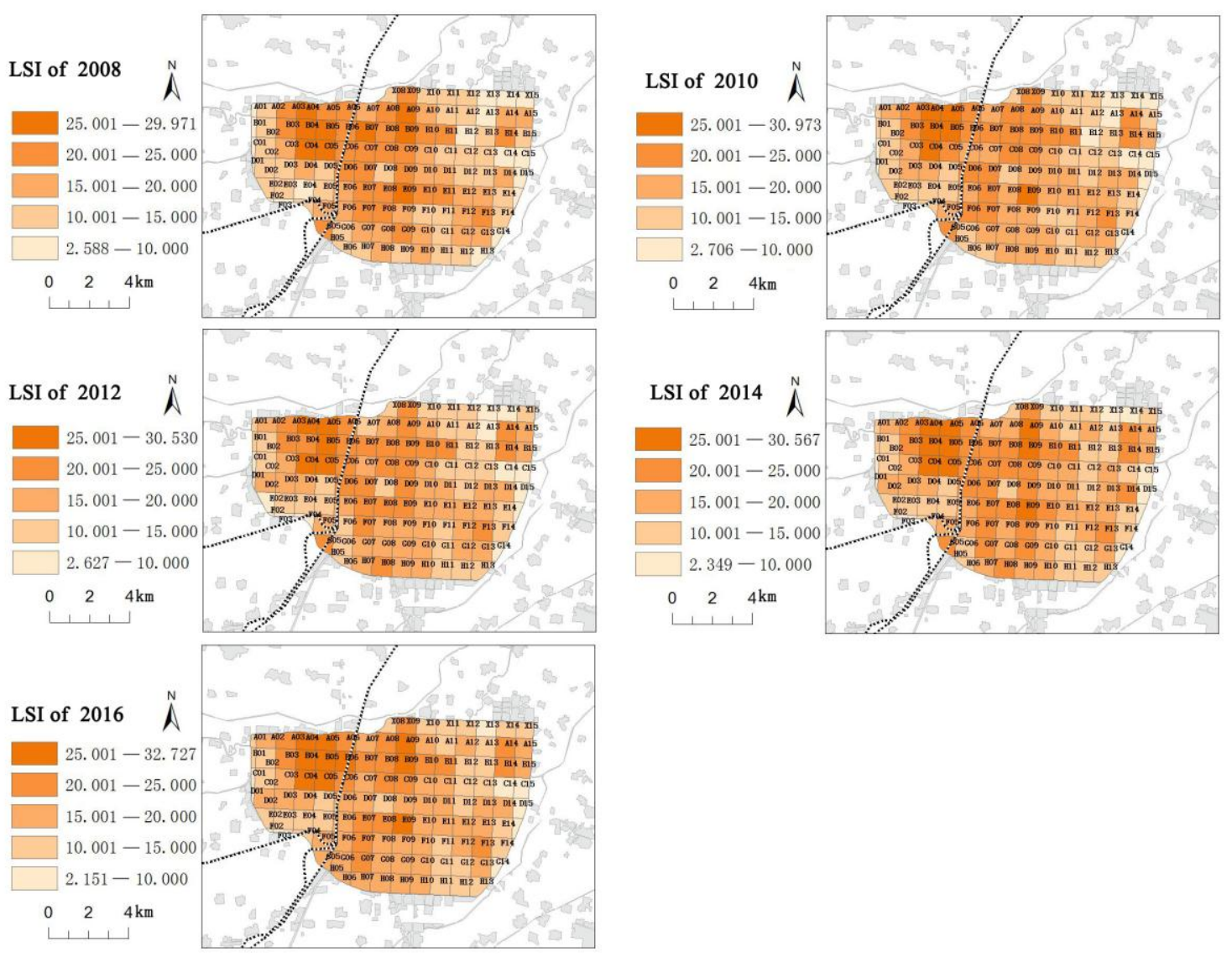

Figure 5. Pattern maps of Landscape shape index based on Xinxiang grid units in 2008-2016

From 2008 to 2016, Figure 6 shows that the high value units of the spreading degree gradually change from the edge of the main urban area to the central zone of the main urban area, which reflects the recent decade of urban construction on the yellow and green space (suburban farmland) erosion. While the contrast between the high value units and the adjacent low value units in the central part of the city is becoming more and more obvious, which reflects that there is still a large imbalance in the urban center area.

According to Figure 7, the main urban area of Xinxiang city as a whole presents the distribution pattern of low central area and high surrounding area. And there are obvious low value continuous units around the railway line and in the northeast of the main urban area. The number of very low value units and very high value units has declined in the last decade, which reflects that the urban construction of the main urban area has entered a more stable period. 

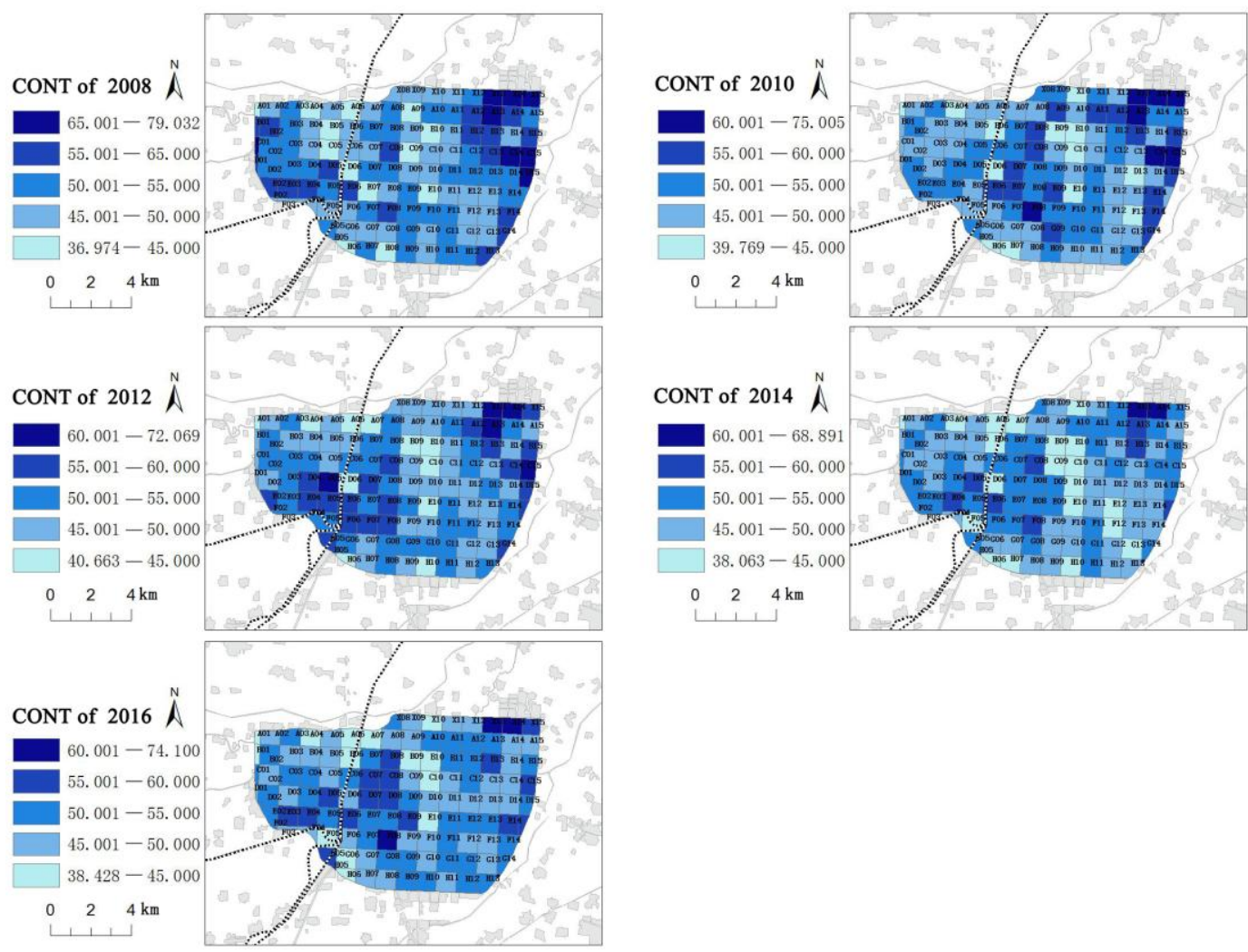

Figure 6. Pattern maps of contagion index based on Xinxiang grid units in 2008-2016

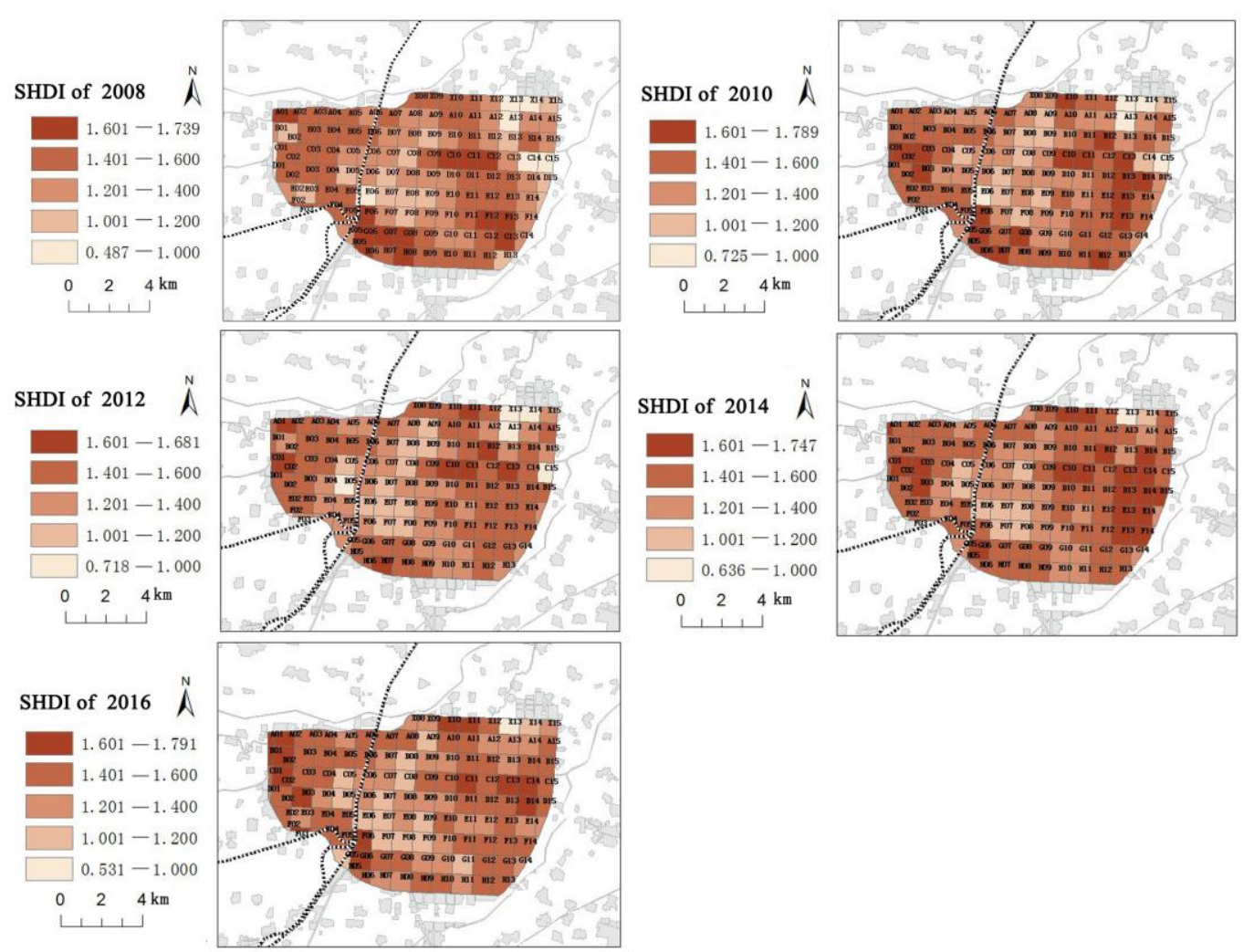

Figure 7. Pattern maps of Shannon diversity index based on Xinxiang grid units in 2008-2016 


\section{Comparative analysis}

It is found that the landscape ecological pattern in the main urban area of Xinxiang is not consistent in macro scale and micro scale, especially in micro scale. On the one hand, the distribution of green open space and blue open space is not balanced. The green coverage rate of old urban area, shantytown and village in city is very low, and it is the key area of ecological development. On the other hand, brown open space is an important factor affecting urban ecological environment, and its volume is very large. The spatial distribution of the blue open space is quite different, so it is recommended to actively repair the city river and build the ecological corridor. The generation of brown open space occurs more frequently in the process of urban renewal and transformation, and the new construction land is more likely to produce brown open space. Moreover, brown open space is also characterized by a rapid transformation into a green open space. The conversion of green open space and brown open space is also worthy of attention.

\section{Conclusions}

The dynamic trajectory of cities can never be fully predicted or controlled, but can and should be influenced or guided in more desirable directions through planning and design activities that are based on urban ecological knowledge and sustainability principles (Ramalho and Hobbs, 2012; Ahern, 2013; Kattel et al., 2013; Wu, 2014; Tanner et al., 2016). For landscape ecological pattern, different scale and precision of observation can obtain different study results. Compared with previous studies, this study is more innovative based on the latest classification of open space and the combination of micro grid units. Based on high resolution image and open space classification, this study classified and extracted the urban space system of the case area. This study analyzed Patch density, Landscape shape index, Contagion index and Shannon's diversity index from the macro level and the micro level. Comparative analysis at the micro level can discover some problem areas that are not found at the macro level. At the micro level, the spatial differentiation characteristics of each index between spatial units are very obvious and they have great changes according to different time period. Therefore, the evaluation of the landscape ecological pattern in the rapidly growing urbanization areas should pay more attention to the spatial unit comparison at the micro level, so as to discover the special areas in the urban space where the landscape ecology is unbalanced and unstable. Urban construction and planning should be able to timely monitor and pay attention to the spatial units with low landscape ecological patterns. These can serve the current "Urban Repair" and "Ecological Restoration" services and improve the overall ecological quality of cities and regions.

\section{REFERENCES}

[1] Ahern, J. (2013): Urban landscape sustainability and resilience: the promise and challenges of integrating ecology with urban planning and design. - Landscape Ecology 28(6): 1203-1212.

[2] Chen, L. D., Li, X. Z., Fu, B. J., et al. (2014): Development history and future research priorities of landscape ecology in China. - Acta Ecologica Sinica 34(12): 3129-3141. 
[3] Forman, R. T. T. (2016): Urban ecology principles: are urban ecology and natural area ecology really different? - Landscape Ecology 31(8): 1-10.

[4] Gao, X. W., Fei, X. Y., Zhang. Z. G. et al. (2014): The aggregation degree evaluation of urban park green space based on convolution method. - Acta Ecologica Sinica 34(15): 4446-4453.

[5] Grafius, D. R., Corstanje, R., Harris, J. A. (2018): Linking ecosystem services, urban form and green space configuration using multivariate landscape metric analysis. Landscape Ecology 33(4): 557-573.

[6] Guo, H. X., Huang, Y., Zhao, D. Q. et al. (2016): Researches on urban compactness based on grid method: a case study of Tianhe District, Guangzhou. - Urban Planning International 31(4): 51-57.

[7] Hong, H. J., Peng, X. C., Chen, Z. L. et al. (2011): The investigation of spatiotemporal patterns of landscape fragmentation during rapid urbanization in Changsha City. Remote Sensing for Land \& Resources (1): 133-137.

[8] Hua, S., Xie, G. X., Shi, L. et al. (2008): Quantitative analysis and optimization of the landscape patterns based on GIS and FRAGSTATS in urban areas: a case in Changsha. Ecology and Environment 17(4): 1554-1559.

[9] Jun-Hyun, K., Gu, D., Wonmin, S. et al. (2016): Neighborhood landscape spatial patterns and land surface temperature: an empirical study on single-family residential areas in Austin, Texas. - International Journal of Environmental Research \& Public Health 13(9): 880 .

[10] Kattel, G. R., Elkadi, H., Meikle, H. (2013): Developing a complementary framework for urban ecology. - Urban Forestry \& Urban Greening 12(4): 498-508.

[11] Kupfer, J. A. (2012): Landscape ecology and biogeography rethinking landscape metrics in a post-fragstats landscape. - Progress in Physical Geography 36(3): 400-420.

[12] Li, Y., Wang, Y. L., Peng, J. et al. (2010): Assessment of urban land suitability for construction in view of landscape ecology: a case study of Dandong City. - Acta Ecologica Sinica 30(8): 2141-2150.

[13] Liu, Q., Yang, Y., Tian, H. (2013): Quantitative study on urban spatial pattern of lanzhou city from the perspective of landscape ecology. - Journal of Arid Land Resources \& Environment 27(1): 47-52.

[14] Mao, D., Liu, Y. P., Wang, F. Z. et al. (2016a): Growth trend analysis of carbon dioxide $\left(\mathrm{CO}_{2}\right)$ emissions and urban green open spaces: a case study of Henan, China. - Oxidation Communications 39(4): 3305-3312.

[15] Mao, D., Zhao, M. L., Liu, J. Y. et al. (2016b): Quality evaluation of provincial urban open space system - a case study from Henan Province, China. - RISTI - Revista Iberica de Sistemas e Tecnologias de Informacao (E8): 131-141.

[16] Midha, N., Mathur, P. K. (2010): Assessment of forest fragmentation in the conservation priority Dudhwa landscape, India using FRAGSTATS computed class level metrics. Journal of the Indian Society of Remote Sensing 38(3): 487-500.

[17] Ojoyi, M. M., Odindi, J., Mutanga, O. et al. (2017): Analysing fragmentation in vulnerable biodiversity hotspots in Tanzania from 1975 to 2012 using remote sensing and FRAGSTATS. - Nature Conservation 16(2): 19-37.

[18] Ramalho, C. E., Hobbs, R. J. (2012): Time for a change: dynamic urban ecology. Trends in Ecology \& Evolution 27(3): 179-188.

[19] Shao, D. W. (2011): Study on the Evolution, Mechanism and Optimization of Urban Open Space Pattern. - Nanjing Normal University, Nanjing.

[20] Tanner, C. J., Adler, F. R., Grimm, N. B. et al. (2016): Urban ecology: advancing science and society. - Frontiers in Ecology \& the Environment 12(10): 574-581.

[21] Turner, M. G. (2003): Landscape ecology: the effect of pattern on process. - Annual Review of Ecology \& Systematics 20(20): 171-197.

[22] Wang, F. Z. (2005): On the optimization of urban opening spatial system in Chinese cities. - Human Geography 20(2): 1-8+113. 
[23] Wang, F. Z., Wang, S. N., Li, M. (2012): Dynamic evolution and optimization of green open space in Luoyang. - Geographical Research 31(7): 1209-1223.

[24] Wang, S. N. (2010): Analysis \& Optimization on Urban Open Space System of Luoyang in Urbanizing Progress. - Henan University, Kaifeng.

[25] Wu, J. (2014): Urban ecology and sustainability: the state-of-the-science and future directions. - Landscape \& Urban Planning 125(2): 209-221.

[26] Wu, J. G. (2007): Landscape Ecology: Pattern, Process, Scale and Hierarchy (2nd ed.). Higher Education Press, Beijing.

[27] Wu, J. G., Xiang, W. N., Zhao, J. (2014): Urban ecology in china: historical developments and future directions. - Landscape \& Urban Planning 125(3): 222-233.

[28] Xiao, D. N., Zhong, L. S. (1998): Ecological principles of landscape classification and evaluation. - Chinese Journal of Applied Ecology 9(2): 217-221.

[29] Yan, J. X., Zhang, J. F., Han, Y. (2018): FRAGSTATS based study of urban green space landscape pattern in Handan City. - Journal of Chinese Urban Forestry 16(1): 127-142. 